\title{
SIMBOLOGÍA DE LAS PERLAS DEL SANTO CÁLIZ DE VALENCIA SEGÚN EL APOCALIPSIS
}

\author{
SYMBOLISM OF THE PEARLS OF THE HOLY CHALICE OF \\ VALENCIA ACCORDING TO THE APOCALYPSE
}

\section{RESUMEN}

El Apocalipsis, que ha ejercido una notable influencia en el arte románico, podría haber inspirado el diseño del Santo Cáliz venerado en la catedral de Valencia, con 24 perlas engastadas en la base. Estas joyas parecen aludir a los 24 ancianos sentados alrededor del trono divino (Ap 4,4), los cuales simbolizan las doce tribus de Israel más las doce tribus del Cordero, es decir, los apóstoles. En la descripción de la nueva Jerusalén se menciona que "las doce puertas eran doce perlas" (Ap 21,21), las cuales han sido interpretadas por los exégetas clásicos como los apóstoles. Por otra parte, Ap 2,17 menciona "una piedrecita blanca" que podría aludir a una perla según Primasio (s. VI). Ésta podría considerarse como tésera o símbolo de las puertas de perla en la Jerusalén celeste. En definitiva, diversos indicios sugieren que la orfebrería del Santo Cáliz de Valencia fue cuidadosamente diseñada con fines catequéticos y no puramente estéticos.

Palabras clave: apocalipsis, exégesis, perlas, Santo Cáliz 
The Apocalypse, which has exerted a notable influence on Romanesque art, might have inspired the design of the Holy Chalice venerated at the Cathedral of Valencia, with 24 pearls mounted at the base. These jewels seem to allude to the 24 elders sitting around the divine throne (Rev 4:4), symbolizing the twelve tribes of Israel plus the twelve tribes of the Lamb, i.e., the apostles. In the description of the new Jerusalem it is mentioned that "the twelve gates were twelve pearls" (Rev 21:21), which have been interpreted by classical exegetes as the apostles. On the other hand, Rev 2:17 mentions "a white pebble" that could refer to a pearl according to Primasius (6th c.). It might be considered as token or symbol of the pearly gates at the heavenly Jerusalem. In short, several indications suggest that the metalwork decorating the Holy Chalice of Valencia was carefully designed for catechetical and not purely aesthetic purposes.

Keywords: Revelation, exegesis, pearls, Holy Chalice

\section{INTRODUCCIÓN}

El Apocalipsis describe diversos elementos arquitectónicos de la Jerusalén celeste (21,10-22), como paralelo a Ez 48,30-35. Se menciona que "las doce puertas eran doce perlas, cada una de las puertas era de una perla"1 $(21,21 a)$. Para comprender el significado de esta metáfora se aportan ciertas pistas: "sobre las puertas doce ángeles y nombres grabados que son las doce tribus de Israel"2 $(21,12)$; "la muralla de la ciudad tenía doce cimientos y sobre ellos los nombres de los doce apóstoles del Cordero" $(21,14)$. Al mencionar los nombres de las doce tribus y de los apóstoles se expresa la continuidad entre el antiguo Pueblo elegido (Ap 7,4-8) y la Iglesia, que se asienta sobre los doce apóstoles de Cristo (Ef 2,20). En definitiva, tradicionalmente se considera que las puertas o accesos de la nueva Jerusalén $(21,21$ a) aluden a los apóstoles. Pero no es evidente por qué estas puertas se describen como perlas. Por otra parte, Ap 2,17 menciona que los vencedores, es decir, quienes perseveren en la fe a pesar de la persecu-

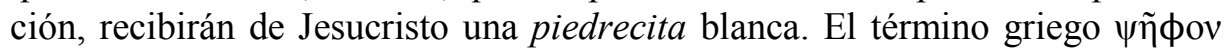
(psēfon) significa guijarro, es decir, un pequeño canto rodado (redondeado), el cual podría asociarse morfológicamente con una perla.

Las perlas eran enormemente costosas en la antigüedad, de modo que son excepcionales las piezas de orfebrería medieval donde se emplean estas joyas

1 Traducción según Eloíno Nácar y Alberto Colunga, Nuevo Testamento (Madrid: BAC, 1980), 763.

2 Cita paralela en Ez 48,31: "Las puertas de la ciudad llevarán los nombres de las tribus de Israel”. 
como distintivo característico de la decoración. Éste es el caso del Santo Cáliz venerado en la catedral de Valencia, con 24 perlas engastadas en el pie que podrían simbolizan los 24 ancianos con vestiduras blancas sentados alrededor del trono divino $(\mathrm{Ap} 4,4)^{3}$. En el presente estudio se revisa la exégesis de Ap 21,21 y su posible paralelismo con Ap 2,17, como basepara esclarecer hasta qué punto el Apocalipsis pudo haber influido en la orfebrería del Santo Cáliz.

\section{EXÉGESIS SOBRE LAS PUERTAS DE PERLA EN AP 21,21}

Varios teólogos como Cesáreo de Arlés ${ }^{4}$ (s. VI), Ecumenio ${ }^{5}$ (s. VI), Andrés de Cesarea (s. VI) ${ }^{6}$, Beato de Liébana ${ }^{7}$ (s. VIII) y San Pedro Damián (s. XI) ${ }^{8}$ consideran que las puertas de la Jerusalén celeste descritas como perlas aluden a los apóstoles, tal como se deriva fácilmente del texto. Según Apringio de Beja (s. VI), esta metáfora "significa que brilla en cada uno de ellos [los apóstoles] una sola perla, que es nuestro Señor Jesucristo"9. San Efrén de Nísibe (s. IV) realiza una reflexión teológica sobre la perla perforada como símbolo de Cristo que, traspasado por los clavos, resplandece con una belleza única ${ }^{10}$.

Beda el Venerable (s. VIII) aporta una visión similar: "así también Él, puesto que es la única perla que el comerciante sabio compró después de haber vendido todo lo que tenía, de igual manera comparte con los suyos el brillo de las perlas"11. El pasaje evangélico al que Beda se refiere (Mt 13,45-46) parece una exageración ya que compara el valor de una perla al de todas las posesiones que alguien puede tener. Sin embargo, la cita puede interpretarse literalmente, pues en época de Jesús las perlas eran enormemente valoradas. Así lo atestigua

3 Hipótesis planteada por Manuel Zarzo, "Simbología Bíblica del Santo Cáliz de la Última Cena Venerado en Valencia”, Cauriensia 13 (2018): 534-535.

4 Cesáreo de Arlés, "Expositio in Apocalypsin", en La Biblia Comentada por los Padres de la Iglesia: Apocalipsis, ed. William C. Weinrich (Madrid: Ciudad Nueva, 2010), 491.

5 Ecumenio, "Oecumenii Commentarius in Apocalypsin", en La Biblia Comentada por los Padres de la Iglesia: Apocalipsis, ed. William C. Weinrich (Madrid: Ciudad Nueva, 2010), 491.

6 Andrés de Cesarea, "Comentario al Apocalipsis", en La Biblia Comentada por los Padres de la Iglesia: Apocalipsis, ed. William C. Weinrich (Madrid: Ciudad Nueva, 2010), 491.

7 Alberto del Campo y Joaquín González, Beato de Liébana: Comentarios al Apocalipsis de san Juan (Cantabria: Valnera, 2006), 404.

8 Jacques Paul Migne, ed., S. Petri Damiani Opera Omnia (París, 1853), 726-728 (sermón 42).

9 Apringio de Beja, Comentario al Apocalipsis, trad. A. del Campo (Estella: Verbo Divino, 1991), 207.

10 Francisco Javier Martínez, "Los Himnos «sobre la Perla» de san Efrén de Nisibe (De Fide LXXXI-LXXXV)", Salmanticensis 38 (1991): 5-32.

11 Beda, "Explicación al Apocalipsis", en La Biblia Comentada por los Padres de la Iglesia: Apocalipsis, ed. William C. Weinrich (Madrid: Ciudad Nueva, 2010), 491. 
Plinio: "las perlas están en el primer puesto del valor de todas las cosas"12. Éstas han sido objeto de comercio desde tiempos antiguos, procedentes del Océano Índico, Golfo Pérsico y Mar Rojo ${ }^{13}$. Su elevado precio se debe a su extraordinaria rareza, ya que las perlas naturales se forman en el interior de moluscos bivalvos como las ostras cuando un cuerpo extraño es recubierto lentamente con capas de nácar. El cultivo industrial de perlas empezó a desarrollarse a finales del s. XIX en Japón, de modo que actualmente su valor es mucho más asequible.

Según Hastings ${ }^{14}$, Ap 21,21 podría referirse a puertas recubiertas de nácar, pero esta interpretación no parece apropiada. Siguiendo el criterio clásico, Henry ${ }^{15}$ y Gill ${ }^{16}$ vinculan esta cita con Jesucristo, la perla de gran valor y belleza ${ }^{17}$, que se presenta a sí mismo como puerta de salvación (Jn 10,9). Ironside $^{18}$ considera que las puertas de perla recuerdan aquella perla de gran valor que es la Iglesia por la cual Cristo lo vendió todo para comprarla y hacerla suya para siempre.

Las perlas ya se empleaban en la antigüedad como aderezo de novia, de modo que su mención en Ap 21,21 es coherente con la descripción de la nueva Jerusalén que se presenta ante el Cordero "como una novia ataviada para su esposo" $(21,2)$, la cual "resplandecía como una piedra muy preciosa" $(21,11)$. Esta majestuosidad expresa quizás la trascendencia de una ciudad que ningún hombre podría edificar, brillante como perla preciosísima ${ }^{19}$. Se muestra la exuberancia derrochada en la ciudad de Dios, $l u z d e l u z^{20}$, con piedras preciosas y armonía de colores ${ }^{21}$. Juan emplea una descripción similar para Babilonia, "la gran ciudad [...] que resplandecía de oro, piedras preciosas y perlas" (Ap 18,16).

12 Plinio, Historia Natural 9.54 (106). El elevado valor de las perlas se deduce de diversas citas bíblicas (Job 28,18; Pr 3,14-15; 20,15; 31,10; 1Tim 2,9; Ap 17,4; 18,12.16) y Eliano también lo menciona: Aeliani, De Natura Animalium (Londres: Frommanni, 1832), lib. X c. 13; lib. XV c. 8.

13 Isidore Singer, ed., The Jewish Encyclopedia, vol. IX (New York: Ktav, 1906), 569. Según Plinio, Historia Natural 12.41 (84), Roma gastaba anualmente unos cien millones de sestercios en el comercio de perlas con la Arabia, India y China. Es una suma muy elevada, pues cuatro sestercios equivalían al jornal de un obrero.

14 James Hastings, ed., Dictionary of the Bible vol. III (New York: Scribner, 1902), 734.

15 Matthew Henry, Concise Commentary on the Whole Bible, vol. VI (Peabody: Hendrickson, 2009), párr. 14.

16 John Gill, Exposition of the Old and New Testaments, vol. VI (Grand Rapids: Baker, 1980), pár. 81 (Ap 21).

17 La primera epístola de Pedro menciona a Cristo como piedra viva, preciosa ante Dios (1Pe 2,4.6).

18 Harry A. Ironside, Estudios sobre el Libro de Apocalipsis (Barcelona: Clie, 1994), 202.

19 Pietro Rossano, Gianfranco Ravasi y Antonio Girlanda, Nuevo Diccionario de Teología Bíblica (Madrid: San Pablo, 1993), 1461. 2035.

20 Nota a Ap 21,11 según Alonso, La Biblia de Nuestro Pueblo (Bilbao: Mensajero, 2011),

21 Xabier Pikaza, Apocalipsis (Estella: Verbo Divino, 2015), 255, 296. 
En resumen, las puertas de perla dan a entender cuán suntuosa será la morada de los santos, pues ya en su misma entrada está configurada de forma incomparablemente bella y valiosa ${ }^{22}$.

La Jerusalén celeste, adornada con gemas $(21,18-21)$, tiene un paralelo con Is 54,12 b: "haré [...] tus puertas de piedras de cuarzo y todo tu término de piedras preciosas". En base a esto, Mathewson ${ }^{23}$ considera que las puertas son descritas como perlas como superlativo de las piedras más valoradas en la época, de color blanco y aspecto brillante, como posible alusión a la gloria de Dios (Ap $21,23)$. Conviene matizar que en la antigüedad las perlas se catalogaban como piedras preciosas ${ }^{24}$, aunque actualmente no se acepta este criterio debido a su origen orgánico.

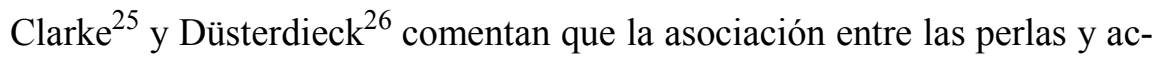
cesos de la muralla $(21,21$ a) se encuentra en la tradición talmúdica como explicación a Is 54,12b. Suele mencionarse la enseñanza del Rabino Yohanan en el Talmud hebreo (Bava Batra 75a): "El Santo, el Bendito, traerá piedras preciosas y perlas que son 30 x 30 codos, y perforará en ellas aberturas de 10 x 20 codos y las colocará en las puertas de Jerusalén" ${ }^{27}$. Otros comentarios rabínicos (Midr. Pss. 87.2 28 ; Pes. K. 18.5 $5^{29}$ ) también interpretan Is 54,12 como "puertas de piedra perforada". Todas estas tradiciones ${ }^{30}$ son posteriores al año 200 d.C. Por tanto, al decirse que "las doce puertas son doce perlas", Fekkes ${ }^{31}$ se pregunta si es una novedad que Juan propone o bien si deriva de la especulación escatológica judía que quizás ya existiese en la época como paralelo a Is $54,12 \mathrm{~b}$.

22 Eduard Schick, El Apocalipsis (Barcelona: Herder, 1974), párr. 41.

23 Dave Mathewson, A New Heaven and a New Earth: The Meaning and Function of the Old Testament in Revelation 21:1 - 22:5 (London: Bloomsbury, 2003), 150.

24 Eliano menciona que la perla es como una piedra (Aeliani, De Natura Animalium, 146-147 [lib. X c. 13]). Ateneo de Náucratis comenta que "entre las piedras la más admirada es la llamada margaritês... con la que se hacen costosos collares" (Athénée, Le Livre III des Deipnosophistes, 45 [c. 93 en texto griego]). 59 (Ap 21).

25 Adam Clarke, Commentary on the Whole Bible, vol. $6 B$ (Dallas: GraceWorks, 2008), párr.

26 Friedrich Düsterdieck, Critical and Exegetical Handbook to the Revelation of John (New York: Funk \& Wagnalls, 1887), 483.

27 Adin Steinsaltz, Koren Talmud Bavli, vol. 27: Bava Batra (Jerusalem: Koren, 2016), n. 75A.

28 William G. Braude, trad., The Midrash on Psalms vol. II (New Haven: Yale, 1959), 75.

29 William G. Braude y Israel J. Kapstein, trad., Pesikta de-Rab Kahana (London: Jewish Society, 1975), 219.

30 Varias leyendas judías y del Cercano Oriente que tratan sobre este tema han sido revisadas por Eric Burrows, “The Pearl in the Apocalypse”, Journal of Theological Studies 43 (1942): 177-179.

31 Jan Fekkes, Isaiah and Prophetic Traditions in the Book of Revelation (New York: Bloomsbury, 1994), 242-244. 


\section{INTERPRETACIÓN DE LA “PIEDRECITA BLANCA" CON UN NOM- BRE NUEVO GRABADO (AP 2,17)}

La simbología de las puertas de perla podría estar relacionada con la siguiente cita: "al vencedor le daré maná escondido ${ }^{32}$; y también una piedrecita blanca, sobre la que irá grabado un nombre nuevo que nadie conoce, salvo el que lo recibe" $(2,17)$. Este nombre se revela en Ap 3,12: “Al vencedor [...] grabaré en él el nombre de mi Dios y el nombre de la ciudad ${ }^{33}$ de mi Dios, la nueva Jerusalén, que baja del cielo enviada por mi Dios, y mi nombre nuevo". Otra cita relacionada es Ap 14,1: "había un Cordero [...] y con él 144.000 que llevaban escrito en la frente el nombre del Cordero y el nombre de su Padre".

Conviene profundizar en el significado del nombre inscrito para comprender por qué Juan menciona un guijarro blanco. Apringio de Beja (s. VI) opina que el nombre nuevo se otorga "para ser sellado con el nombre divino y adornado con la gloria de la inmortalidad [...]. «Y mi nombre nuevo». Nada es viejo en Dios, que no envejece con la edad, sino que siempre es nuevo el nombre del Señor" ${ }^{4}$. Primasio (s. VI) comenta lo siguiente: "«Y escrito en la piedrecita un nombre nuevo», es decir, el de cristiano; por eso leemos: «Te llamarán con un nombre nuevo, que pronunciará la boca del Señor»" ${ }^{35}$. La cita que este autor menciona es Is 62,2. Además de este paralelo, suelen sugerirse los siguientes: "pero a sus siervos les dará un nombre nuevo" (Is 65,15); "yo he de darles en mi templo y en mi ciudad monumento y nombre mejor que hijos e hijas; nombre eterno les daré que no será borrado" (Is 56,5). En base a estos paralelos, Pikaza ${ }^{36}$ considera que el nombre escrito en el guijarro es el de Dios y de Cristo (como en 3,12), siendo al mismo tiempo el de cada uno de los llamados a la gloria. Este nombre esculpido indica la participación del cristiano en los bienes que el Señor concede sólo a los vencedores, quienes llevarán el nombre de Dios como cosa que le pertenece y le está consagrada ${ }^{37}$. Podría considerarse cierta vinculación con Lc 10,20: "alegraos de que vuestros nombres estén escritos en los cielos".

El nombre propio es signo de identidad y en ocasiones es empleado por los profetas como símbolo eficaz (Is $8,3-4 ; 9,5$; Os $1,4.6 .9 ; 2,1.3 .25$ ). En la cultura hebrea, invocar un nombre propio es como hacer presente a quien lo lleva. De

32 Según la Biblia de Jerusalén, 1821, al decir escondido podría referirse al maná, guardado dentro del Arca de la Alianza (Hb 9,4), que Jeremías escondió (2Mac 2,4-8).

33 El nombre de la ciudad de Dios tiene varios paralelos (Is 1,26; 60,14; 62,12, Ez 48,35, Jer $3,17 ; \mathrm{Ba} 5,4)$.

34 Apringio de Beja, Comentario al Apocalipsis, 96.

35 Primasio, "Commentarius in Apocalypsin", en La Biblia Comentada por los Padres de la Iglesia: Apocalipsis, ed. William C. Weinrich (Madrid: Ciudad Nueva, 2010), 78.

36 Pikaza, Apocalipsis, 60.

37 Comentario a Ap 2,12-17 según la Biblia de Navarra, 8064. 
ahí la reverencia otorgada al nombre de Dios (Sal 102,16; 124,8; 148,13; Prov 18,10; Is 59,19; Mi 4,5; 5,3; Sof 3,12, Lv 24,16) y la importancia de edificar una Casa como "morada de su nombre" (Dt 12,5.11.21; 1Cro 22,7-10, 2Cro 2,3-5). Por eso, suprimir el nombre equivale a exterminar la existencia (Dt 9,14; 29,19; Jos 7,9; 2Re 14,27; Ap 3,5).

El hecho de imponer un nuevo nombre representa una nueva identidad o ministerio (Gn 17,5.15; 32,29; Mt 1,21; Jn 1,42) que, respecto al nombre nuevo entregado a los vencedores (Ap 2,17), es símbolo de la visión beatífica en el Paraíso celestial que sacia totalmente las ansias y deseos del bienaventurado y que se manifiesta sólo en la vida futura (1Jn 3,2; 1Cor 13,9-12). Los vencedores que se han identificado con el mismo Cristo en el sufrimiento por causa de la fe se identifican también con el nombre del Hijo de Dios, pues los justos en el cielo son propiedad de Dios, quien les otorga el derecho de residir eternamente en la Jerusalén celestial. El color blanco de la piedra, símbolo de las vestiduras blancas de los santos (Ap 3,5; 7,13; 19,8.14), representa su pureza en el cielo $(4,4)$ y la gloria de la victoria $(6,2)$. El nombre nuevo tiene sentido en la re-creación de Dios: "voy a crear un nuevo cielo y una nueva tierra" (Is 65,17; Ap 21,1).

\section{EXÉGESIS MODERNA SOBRE LA "PIEDRECITA BLANCA" EN AP 2,17}

Esta cita podría estar inspirada en la costumbre pagana bastante extendida de llevar amuletos con algún nombre enigmático escrito en ellos; se creía que quien conociera ese misterioso nombre podía protegerse de los malos espíritus. Por el contrario, Cristo afirma que únicamente su nombre, "que sólo él conoce" (Ap 19,12), es el que proporciona verdadera protección a cuantos creen en é ${ }^{38}$ (Mc 16,17; Jn 1,12; Hch 2,21; 2Tm 2,19).

También era costumbre recompensar a los atletas vencedores en los juegos, quienes eran invitados en banquetes festivos. Este hecho resulta relevante para interpretar Ap 2,17 al mencionarse que los vencedores serán obsequiados con maná, pan bajado del cielo (Ex 16,15) que alude a la Eucaristía (Jn 6,27-58), de la que puede participar quien sea cristiano. El emperador Tito (s. I d.C.) acostumbraba a lanzar a la palestra pequeñas bolas de madera con inscripciones de comida, ropa o dinero, como si fueran vales que los competidores podían canjear

38 Jean-Louis d'Aragon, “Apocalipsis”, en Comentario Bíblico San Jerónimo, tomo IV, ed. Raymond E. Brown, Joseph A. Fitzmyer y Roland E. Murphy (Madrid: Cristiandad, 1972), 546. 
por dichos productos ${ }^{39}$. El reparto entre la multitud de estos vales como dádiva era habitual por los emperadores o personajes ilustres para obtener el favor popular $^{40}$.

Diversos autores de siglos precedentes ${ }^{41}$ consideran que la "piedrecita blanca" podría aludir a una tésera. Estas piezas (tessera hospitalis) tienen su origen en los símbolos griegos ( $\sigma 0 ́ \mu \beta 0 \lambda o v)$. Este término se empleaba originariamente en la realización de contratos o como signo de reconocimiento entre hospedador y huésped. Consistía en romper una pieza de cerámica o metal de tal manera que cada una de las dos partes (viajero y hospedador, o bien el vendedor y comprador) se quedaban con una de ellas; la reunión futura de las dos mitades complementarias en una sola pieza era la prueba de la antigua hospitalidad establecida o servía de legitimación del convenio pactado. A partir de este significado primigenio, los griegos llamaban símbolos a los contratos, contraseñas, salvoconductos, billetes de entrada a espectáculos, distintivos, estandartes, etc. $^{42}$. Al mencionarse el maná como obsequio a los vencedores $(2,17)$, la "piedrecita blanca" puede interpretarse como una tésera que quien la recibe debe conservar $^{43}$, a modo de vale que otorga el derecho a recibir la recompensa, o como billete (tique) o contraseña ${ }^{44}$ de entrada que reciben los cristianos para participar en el banquete de bodas del Cordero y tener acceso a la nueva Jerusalén. Esta exégesis se comenta en diversas versiones de la Biblia ${ }^{45}$, pero no termina de encajar con el concepto griego de $\psi \tilde{\eta} \phi o v$ (guijarro).

Barnes ${ }^{46}$ y Elsner ${ }^{47}$ mencionan que los griegos y romanos acostumbraban a echar a suertes con pequeñas piedras blancas o alubias, llamadas $\psi \tilde{\eta} \phi o \varsigma$, sobre las cuales se escribían nombres. También los judíos tenían costumbre de echar a suertes, pues pensaban que la providencia divina intervenía de modo especial

39 Mencionado por Juan Xifilino, historiador del s. XI, en su epítome de la Historia Romana de Dión Casio. 650.

40 Anthony Rich, A Dictionary of Roman and Greek Antiquities (London: Longmans, 1873),

41 Hammond (1653), Eichhorn (1791) y Grotius (1830), citados por Düsterdieck, Revelation of John, 147.

42 Rich, Dictionary of Roman and Greek Antiquities, 650. Contiene referencias de autores clásicos a los distintos tipos de tessera empleados en la antigüedad.

43 Heinrich Ewald, Die Johanneischen Schriften: Apokalypse, vol. II (Göttingen: Dieterischenen, 1862), 136.

44 Sebastián Bartina, “Apocalipsis de San Juan”, en La Sagrada Escritura, Nuevo Testamento III (Madrid: BAC, 1962).

45 Alonso, Biblia de Nuestro Pueblo, 2011; Biblia de Navarra, 8064; Biblia de la CEE, 2077; Nácar y Colunga, Nuevo Testamento, 719.

46 Albert Barnes, Notes on the New Testament (Dallas: GraceWorks, 2008), párr. 133.

47 Elsner, Observationes Sacrae in Novi Foederis Libros (citado por Düsterdieck, Revelation of John, 147). 
en lo que tocaba en suerte (Lv 16,8-10; Num 26,55-56; Jos 14,2; Hch 1,26). El Sumo Sacerdote llevaba en su pectoral dos piedras denominadas Urim y Tummim (Ex 28,30), que se empleaban para buscar las manifestaciones de la voluntad divina y tomar decisiones sobre una pregunta concreta, similar a una moneda que cae de cara o cruz (Num 27,21; 1Sam 14,41; 28,6; Neh 7,65) ${ }^{48}$.

Antiguamente se empleaban también guijarros ( $\psi \tilde{\eta} \phi o v)$ en los juicios para votar y calcular el número de votos ${ }^{49}$. El acusado era condenado con guijarros negros y absuelto con los blancos ${ }^{50}$. Por ello, $\psi \tilde{\eta} \phi o \varsigma$ también significa voto o veredicto $^{51}$. En Hch 26,10 se menciona que Pablo contribuía a condenar a los

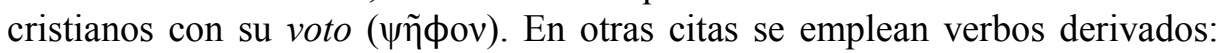

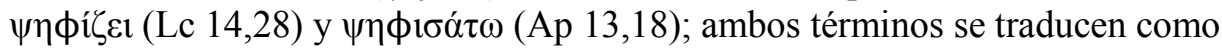
calcular, pues su interpretación precisa sería usar guijarros para contar o enumerar, aunque también pueden significar emitir un voto echando el guijarro dentro de la urna. Teniendo en cuenta este concepto de $\psi \tilde{\eta} \phi o v$, diversos autores ${ }^{52}$ han relacionado Ap 2,17 con la costumbre clásica de emitir un voto favorable en los juicios con guijarros blancos. De este modo, la "piedrecita blanca" podría significar el juicio de Cristo que otorga a los vencedores la sentencia de la salvación, en base a la esperanza cristiana $(\operatorname{Rm} 8,17)$.

\section{LA "PIEDRECITA BLANCA" COMO POSIBLE SÍMBOLO DE LAS PUERTAS DE PERLA}

Según Ecumenio ${ }^{53}$, el guijarro se entrega "a quien ha vencido y brilla en la gloria". Cesáreo de Arlés ${ }^{54}$ cree que esta piedrecita significa "un cuerpo emblanquecido por el bautismo". Primasio comenta lo siguiente: "«Le daré también una piedrecita blanca», es decir, la adopción de los hijos de Dios ${ }^{55}$. En efecto, esta piedrecita es una gema preciosa, que puede entenderse como aquella

48 Un paralelo entre ambas piedras (Urim y Tummim) y la "piedrecita blanca" ha sido sugerido por Gill, Exposition of the Old and New Testaments, párr. 78 (Ap 2).

49 Joseph Thayer, Greek-English Lexicon of the New Testament (Peabody: Hendrickson, 1995), voz: $\psi \tilde{\eta} \phi$ os.

50 Franz Passow, Handwörterbuch der Griechischen Sprache, vol. III (Leipzig, 1824), 2574. Ver también: Clarke, Commentary on the Bible, párr. 44 (Ap 2).

51 Diccionario de griego, voz $\psi \tilde{\eta} \phi o s$, http://www.dicciogriego.es/index.php\#lemas?lema= $1200 \& n=1200$

52 Erasmus (1535), Zeger (1553), Aretius (1583), Calovius (1676), Vitringa (1705) y Wolf (1741), citados por Düsterdieck, Revelation of John, 147.

53 Ecumenio, "Commentarius in Apocalypsin," 77.

54 Cesáreo de Arlés, "Expositio in Apocalypsin," 78.

55 Esta interpretación ha sido adoptada por muchos exégetas según Düsterdieck, Revelation of John, 147. 
que el comerciante encontró y comparó a todas sus posesiones. Otra traducción pone margarita" ${ }^{\text {"5 }}$. Esta exégesis es relevante, pues se vincula la piedrecita con la gema de Mt 13,45-46 que es una perla. Al mencionar que "otra traducción pone margarita" (perla) se refiere a una traducción anterior a la Vulgata ${ }^{57}$ (s. IV), lo que se conoce como Vetus Latina. Posiblemente de ahí proviene su idea de asociar el guijarro con una perla. En consonancia con esta interpretación, Pikaza ${ }^{58}$ sugiere que el guijarro blanco sería símbolo de las puertas de perla. Según este autor, Cristo ofrece al vencedor el maná, banquete de gracia, y la piedra blanca de entrada en la ciudad de las piedras preciosas (Ap 21,15-21). Como conclusión, Juan podría haber tenido en mente el versículo de Ap 2,17 cuando describe posteriormente las puertas del cielo como perlas $(21,21 \mathrm{a})$.

Varios pasajes del Antiguo Testamento (AT) relacionan ciertas piedras con las doce tribus de Israel. Por ejemplo, cuando las aguas del Jordán se separaron delante del Arca de la Alianza, Josué levantó doce piedras, una por cada tribu, como memorial perpetuo del suceso (Jos 4,2-9). También Moisés alzó un altar y doce estelas ${ }^{59}$ por las doce tribus de Israel como memorial de la alianza con Dios (Ex 24,3-4). Por otra parte, el pectoral del Sumo Sacerdote estaba formado por doce piedras preciosas distintas, cada una representativa de una de las doce tribus, cuyo nombre estaba inscrito sobre la piedra (Ex 28,16-21; Si 45,10-11). Por este motivo, la "piedrecita blanca" podría aludir a estas doce gemas ${ }^{60}$, indicando la dignidad sacerdotal de los vencedores (1Pe 2,5.9), que tienen acceso a Dios (Ap 1,6;5,10) ${ }^{61}$. Dado que las doce tribus de Israel son figura de los doce apóstoles en el nuevo testamento (NT), la simbología entre éstos y las piedras preciosas no es una novedad que Juan propone.

Cristo, constituido por Dios como juez de vivos y muertos (Hch 10,42; Jn $5,22.27$; 2Co 5,10), entrega el guijarro blanco a los que han sido fieles al evangelio. Éste es el voto favorable para la salvación eterna, pues se empleaban guijarros blancos y negros en los juicios para calcular los votos condenatorios y absolutorios. Siendo un solo juez, tiene sentido pensar en un solo guijarro. Este voto o veredicto es también tésera o símbolo, es decir, billete de admisión o salvoconducto para entrar en la Jerusalén celeste. En cierto modo, el guijarro

56 Primasio, "Commentarius in Apocalypsin", 78.

57 La Vulgata traduce Ap 2,17 como "et dabo illi calculum candidum". El término calculum significa guijarro, según el dicccionario Glosbe de latín, https://es.glosbe.com/la/es/calculus.

58 Pikaza, Apocalipsis, 60.

59 Monumento conmemorativo, es decir, como hito o mojón en memoria de lo sucedido. Era tradición entre los pueblos nómadas (Gn 31, 44-45; Jos 4,7).

60 Interpretación sugerida por Ewald (1828), Züllig (1834), Ebrard (1853) y Kliefoth (1874), citados por Düsterdieck, Revelation of John, 147.

61 Catecismo de la Iglesia Católica 1546. 
blanco y la perla encajan simbólicamente, es decir, como las dos partes de un símbolo $^{62}$, porque ambas piedras son redondeadas, de igual color y tamaño pequeño. En este sentido, cuando el vencedor recibe este billete para participar en el banquete celestial, esta tésera es complementaria y encaja con las puertas de perla de la nueva Jerusalén (21,21a), legitimando el acceso a la ciudad celestial (Sal 118, 18-20).

La cita de Ap 2,17 podría interpretarse del siguiente modo: "al vencedor le daré también mi voto favorable, como salvoconducto para entrar por las puertas de la nueva Jerusalén". Por otra parte, Juan describe a doce ángeles situados sobre las puertas de la ciudad $(21,12 a)$, los cuales según Pikaza ${ }^{63}$ ofician de porteros celestes y guardianes ${ }^{64}$ de la nueva ciudad, impidiendo la entrada de los enemigos y dejando entrar a quienes han sido dignos del banquete celestial $(19,9)$, que son los que poseen el salvoconducto, es decir, la tésera blanca con el nombre grabado.

\section{INFLUENCIA DEL APOCALIPSIS EN LA ICONOGRAFÍA DEL SANTO CÁLIZ DE VALENCIA}

El Comentario al Apocalipsis escrito en el s. VIII por Beato, monje de Liébana (Cantabria), es famoso por los numerosos manuscritos bellamente ilustrados en que fue copiado entre los siglos X - XII, denominados "beatos". La difusión de estas ilustraciones explica en parte la notable influencia del Apocalipsis en el arte románico español, lo cual se refleja por ejemplo en el pantocrátor ${ }^{65}$ : Cristo sentado en un trono $(5,13 ; 6,16 ; 7,15 ; 21,5)$ con un libro en la mano $(5,1.7)$, rodeado de una mandorla $(4,3)$ y los cuatro vivientes $(4,6-8)$. Estos vivientes o tetramorfos (Ez 1,5-10) aparecen también en algunos cálices románi$\cos ^{66}$. En piezas de orfebrería medieval, el uso de perlas como elemento simbólico inspirado en el Apocalipsis ha sido poco estudiado ya que su uso no era habitual debido a su elevado precio. Una de las rarísimas excepciones es el Santo

62 El símbolo griego generalmente era la mitad de una pieza quebrada, de modo que las dos partes complementarias eran prenda o legitimación del acuerdo alcanzado.

63 Pikaza, Apocalipsis, 252.

64 Cita paralela en Is 62,6: "Sobre los muros de Jerusalén he apostado guardianes".

65 La palabra pantocrátor (todopoderoso) se menciona en Ap 1,8; 4,8;11,17; 15,3; 16,7.14; $19,6.15$ y 21,22 .

66 El tetramorfos está representado en el cáliz del Abad Pelagio (1097 - 1121) de procedencia leonesa, http://cartelen.louvre.fr/cartelen/visite? srv $=$ car_not_frame\&idNotice=5191 (actualmente en el Museo del Louvre) y en el cáliz del Monasterio de sā Miguel de Refoios (Portugal, s. XII); Museo Nacional de Machado de Castro, http://www.museumachadocastro.gov.pt/Data/ContentImages/Destaques/calice.jpg 
Cáliz venerado en la catedral de Valencia desde 1437, pues la base, de oro finamente burilado, está decorada con 24 perlas engastadas aunque actualmente falta una. La copa superior, tallada en piedra de ágata, es la que empleó Jesús en la Última Cena según la tradición, y que posteriormente utilizaron san Pedro y los primeros papas hasta el año 258 .

La pieza intermedia de este cáliz es de oro y en ella está representado el tetramorfos ${ }^{67}$, por medio de cuatro aros circulares nielados en forma de ruedas. Ubicadas justo debajo de la copa, estas ruedas ${ }^{68}$ simbolizan posiblemente el carro-trono de Dios (Ez 1,15-21; 10,9-13) y se asocian con el tetramorfos en muchos beatos como el de Valcavado (s. X), Girona (s. X), Facundo (s. XI), Manchester (s. XII), etc. Esta evidencia de que la orfebrería del Santo Cáliz está inspirada en los beatos hace elucubrar que las 24 perlas podrían simbolizar los 24 ancianos con vestiduras blancas y coronas de oro sentados alrededor del trono divino (Ap 4,4, cf. Is 24,23). Estos ancianos simbolizan los 24 grupos de porteros del Templo (1Cro 26,1-19) o bien las doce tribus de Israel más las doce tribus del Cordero, es decir, los apóstoles (Mt 19,28). Los exégetas clásicos consideran que las perlas mencionadas en Ap 21,21 aluden a los apóstoles, lo cual es coherente con esta hipótesis. Quizás para resaltar la diferenciación de $12+$ 12 perlas, alusivas al AT (Ap 21,12) y NT $(21,14)$ respectivamente, se eligiese una base con forma elíptica. Esta característica es muy inusual en cálices eucarísticos, pero podría relacionarse con la iconografía románica, pues hacia el s. XI - XII cuando supuestamente se montaron las perlas, el pantócrator se representaba en el sur de Francia rodeado de una mandorla elíptica ${ }^{69}$.

Un manuscrito ${ }^{70}$ medieval del Apocalipsis contiene una ilustración realizada hacia 1429-1435 que representa a 24 ancianos sentados alrededor del trono del Cordero. En la orla de este dibujo, obra de Péronet Lamy, están representadas las mismas rosetas nieladas en el vástago del Santo Cáliz, lo cual apunta a éste como fuente de inspiración de la ilustración y hace sospechar que estos ancianos están simbolizados en las 24 perlas del Cáliz. Las perlas más antiguas están montadas por medio de una perforación vertical mediante un vastaguillo de oro, de modo que en su parte superior queda visible el extremo, el cual podría

67 Zarzo, "Simbología Bíblica del Santo Cáliz", 535.

68 En el Beato de San Millán (Academia de la Historia de Madrid: códice 33, folio 921d), fechado hacia 970-1000, se representan los cuatro vivientes dentro de una rueda. Una ilustración equivalente aparece en el Codex Purpureus Rossanensis, s. V-VI (museo de la Catedral de Rossano, Italia).

69 Así aparece en el dintel de la abadía de Saint-Génis-des-Fontaines (pirineos franceses), datado en el año 1020, y en un portal de la iglesia de san Trófimo en Arlés (s. XII).

70 Apocalipsis figurado de los Duques de Saboya (Códice Vit. I de la biblioteca de El Escorial). La ilustración mencionada se encuentra en el folio $5 \mathrm{v}$. 
representar la corona de oro citada en Ap 4,4. Ésta es señal de victoria con Jesucristo vencedor (Ap 6,2; 14,14); como el triunfo que recibían los atletas vencedores (2Tim 2,$5 ; 1$ Cor 9,25), así tomarán la corona quienes se mantengan firmes en la fe (1Pe 5,4; St 1,12; 2 Tim 4,8; Ap 3,11).

El pie del Santo Cáliz es en realidad una naveta invertida de piedra calcedonia en la cual existe una inscripción esgrafiada que ha sido interpretada como "Jesús Dios" en árabe ${ }^{71}$; y curiosamente también se puede leer la misma expresión en hebreo (Yoshua Yahweh) cuando ésta se refleja en la copa superior a modo de imagen especular ${ }^{72}$. Al parecer, esta inscripción fue diseñada por Pedro Alfonso de Huesca ${ }^{73}$, escritor judío educado en al-Ándalus, erudito en árabe ${ }^{74}$, hebreo $^{75}$ y exégesis cristiana ${ }^{76}$. Tenía una estrecha vinculación ${ }^{77}$ con el rey Alfonso I "el Batallador", pues fue su padrino de bautismo en 1106. Por tanto, la inscripción probablemente se ejecutó durante este reinado, entre 1104 y 1134. De hecho, una lápida funeraria encontrada en Alcoy datada en 1157 presenta prácticamente todas las letras idénticas a las encontradas en la piedra del Santo Cáliz $^{78}$. Existe cierta evidencia de que hacia 1200 - 1220 ya existía dicho epígrafe sobre la piedra, pues en esas fechas se escribió el romance Parzival de Eschenbach donde supuestamente se hace alusión a esta inscripción en ciertos $\operatorname{versos}^{79}$.

71 Agustín Blasco, "La Doble Interpretación de la Inscripción del Pie del Santo Cáliz", Linteum 60 (2016): 13-18, 23-27. Esta interpretación en árabe ha sido matizada por Gabriel Songel, "Aproximación a la Autoría y Significado de la Inscripción del Santo Cáliz de Valencia", Archivo de Arte Valenciano 99 (2018), 28-29, 33.

72 Gabriel Songel, "Patrón de Diseño del Santo Cáliz de Valencia", Revista Bellas Artes 13 (2016), 225-230.

73 Songel, “Autoría y Significado de la Inscripción del Santo Cáliz”, 30-32.

74 Pedro Alfonso de Huesca, Diálogo contra los Judios, trad. Esperanza Ducay (Huesca: Instituto de Estudios Altoaragoneses, 1996), 291. En esta famosa obra apologética escrita en latín en 1110 , el autor demuestra que conoce el Corán y afirma que se había criado con los sarracenos, lo cual revela su dominio del árabe.

75 Pedro Alfonso tenía un excepcional conocimiento del texto hebreo del Talmud, pues dice de sí mismo: "en otro tiempo, eras docto en los escritos de los profetas y en las palabras de nuestros doctores; (...) en las sinagogas, predicabas a los judíos (...), instruías a tus compañeros" (Pedro Alfonso, Diálogo, 201).

76 En su obra aparece varias veces la reflexión teológica de Jesús como Hijo de Dios (Pedro Alfonso, Diálogo, 255, 266, 267, 367, 368).

77 Probablemente sirvió en algún puesto de la corte, pues su conversión causó polémica entre los judíos, quienes le acusaban de haberse convertido por avidez de poderes mundanos (Pedro Alfonso, Diálogo, 199).

78 Blasco, "Inscripción del Pie del Santo Cáliz", 16.

79 Versos referidos al Santo Grial que pueden traducirse como: "Al borde de la piedra, con caracteres un epitafio, dice su nombre y su condición". Véase: Blasco, "Inscripción del Pie del Santo Cáliz”, 28-31. 
Posiblemente la inscripción fue epigrafiada para plasmar la tradición de que la copa había sido empleada por Jesús - Dios; no obstante, podría estar inspirada en el Apocalipsis, a partir del paralelo entre las perlas mencionadas en Ap 21,21 y la "piedrecita blanca" de 2,17, que contiene un nombre grabado al cual se hace referencia en 3,12 y 14,1: "el nombre del Cordero" (Yoshua) "y el nombre de su Padre" (Yahweh). La asombrosa coincidencia de esta cita $(14,1)$ con la inscripción del Santo Cáliz permite especular que las 24 perlas podrían aludir a la "piedrecita blanca" que Cristo entrega a los que perseveran en la fe, con un nuevo nombre grabado como símbolo de pertenencia al Cordero $(2,17)$. En palabras de Pedro Alfonso, "acerca de los que habían de creer: «Y llamará a sus siervos con otro nombre». Pues, siendo siervos de Cristo, por Cristo se llamarán cristianos" ${ }^{\prime 80}$. En esas perlas, que posiblemente aluden a los 24 tronos (Ap 4,4), estaría representada toda la humanidad glorificada $(3,21 ; 7,13-15)$, encabezada por los apóstoles. Respecto al versículo de Ap 2,17, Beato de Liébana menciona:

La piedrecita es una piedra blanca, de la que dice el apóstol: "vosotros, cual piedras vivas, construid el templo de Dios". También las piedras preciosas representan a los confesores, los apóstoles, los sacerdotes y todos los justos [...]. Con razón, pues, se dice: "le daré una piedrecita blanca", es decir, le concederé sentarse con los poderosos de mi pueblo, que son los Apóstoles, y le haré heredero del trono de la gloria. ${ }^{81}$

Este autor opina que Cristo entrega el guijarro a los vencedores porque cada cristiano está llamado a ser piedra viva del templo de Dios (1Pe 2,5). Este templo, morada de Dios con los hombres (Ap 21,3.22), es visualizado por Juan como ciudad de piedras preciosísimas, de modo que tiene sentido considerar también la piedrecita como una gema. Tratándose de un guijarro pequeño blanco, resulta bastante obvia su vinculación con las perlas. Además, Beato asocia el guijarro con los apóstoles, herederos del trono de gloria como posible alusión a Ap 4,2-4, lo cual resulta relevante ya que la misma interpretación se deriva de Ap 21,21a. Dado que este comentario circulaba por los monasterios del norte de la península Ibérica en los siglos XI - XII, mismo territorio donde se encontraba el Santo Cáliz en la época, no es de extrañar que el texto e incluso quizás alguna de sus ilustraciones sirviese de inspiración para diseñar la orfebrería de este insigne cáliz. De hecho, dos beatos ${ }^{82}$ realizados en León, contienen una

80 Pedro Alfonso, Diálogo, 263. La cita entre comillas corresponde a Is 65,15. Este comentario es muy similar al de Primasio referido a la "piedrecita blanca" de Ap 2,17.

81 Del Campo y González, Beato de Liébana: Comentarios al Apocalipsis, 154.

82 (a) Beato de Facundo (s. XI), Biblioteca Nacional Española, códice Vitr/14/2, http://www.atopon.it/wp-content/uploads/2012/01/ist_rel2.jpg; (b) Beato de Morgan (s. X), folio 87, Pierpoint Morgan Library (Nueva York, ref. MS 644), http://www.itacaeventi.it/wp-content/ uploads/ 2008/04/la-parola-accade-immagine.jpg. 
ilustración sobre la adoración del Cordero donde la aureola que rodea la escena presenta 24 estrellas ${ }^{83}$ blancas, las cuales podrían simbolizar los 24 ancianos

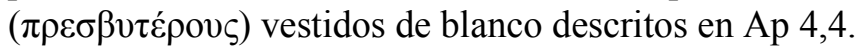

Durante el reinado de Alfonso "el Batallador", el Santo Cáliz se encontraba seguramente en el monasterio de San Juan de la Peña (Huesca), panteón de reyes y nobles de Aragón. Resulta difícil elucubrar qué motivación pudo existir para grabar tan meticulosa inscripción en un cáliz recluido en este oscuro monasterio de restringido acceso. Lo más lógico es suponer que dicha grabación se efectuó en la naveta invertida cuando ésta fue insertada en la base del Santo Cáliz. Esta hipótesis coincide con la datación propuesta por Beltrán ${ }^{84}$ para la naveta del pie con reborde de oro, entre los siglos X al XII, así como de las piedras y perlas, fechables entre los siglos XII al XIV. No obstante, es dudoso si las perlas se añadieron en ese momento o si ya existían en la configuración anterior del Cáliz.

Esta remodelación quizás pretendiese ensalzar la importancia de la reliquia, dotándola de un relicario diseñado a modo de sede de la copa superior, quizás basándose en la descripción de Ap 4,2-6. La Península Ibérica se encontraba bajo la Reconquista cristiana frente al poder musulmán, en cuya contienda las reliquias jugaron un papel fundamental como símbolo de la religión que se imponía progresivamente. En este contexto, y dado que Alfonso I era muy piadoso pues legó su reino a tres órdenes de caballeros cristianos, es admisible que decidiese embellecer la orfebrería del Santo Cáliz, y no se descarta que Pedro Alfonso participase en dicho diseño ${ }^{85}$. Curiosamente, la naveta invertida y la copa de ágata adquieren una coloración muy similar cuando se iluminan con luz transversal. Ambas aportan al Santo Cáliz cierto aspecto simétrico ${ }^{86}$, lo cual era habitual en los cálices mozárabes de la época como el de Santo Domingo de Silos, datado hacia 1041-1050.

Asumiendo que las perlas simbolizan los cristianos que alcanzan la salvación, tal vez con la remodelación del Cáliz se pretendía transmitir esa misma esperanza a los fieles, lo cual va unido con la necesaria penitencia. Este carácter

83 La mujer coronada de doce estrellas (Ap 12,1) puede interpretarse como la Iglesia presidida por los doce apóstoles. Por tanto, las 24 estrellas en estas aureolas podrían aludir a quienes presiden la Iglesia como cabeza de los hijos de Dios, "numerosos como las estrellas", llamados a la patria celestial (Hb 11,12.16).

84 Antonio Beltrán, Estudio sobre el Santo Cáliz de la Catedral de Valencia (Valencia: Instituto R. Chabás, 1984), 104.

85 Además de teólogo, tenía una amplia formación en ciencias árabes y era "perito (...) en las artes liberales" (Pedro Alfonso, Diálogo, 199), entre las cuales se engloba la aritmética y geometría.

86 La configuración del Santo Cáliz es similar al cáliz representado en el Púlpito de los Evangelios de la Catedral de Ravello (Italia), fechado en 1272, https://www.alamy.es/imagenes/ravellocathedral.html. 
penitente se refleja en un dintel ${ }^{87}$ de la catedral de Jaca (Huesca), donde se lee: "ven aquí suplicante (...). Purifica de vicios tu corazón para que no perezcas de una segunda muerte", en alusión al infierno ${ }^{88}$. La hipótesis de que tanto el Santo Cáliz como este dintel se diseñasen con un sentido penitente es original, pero existe vinculación entre ambos, pues el rey Sancho Ramírez inició la construcción de la catedral de Jaca con el deseo de albergar allí el preclaro Cáliz. Las obras se paralizaron en 1082 y fueron reanudadas posteriormente por Alfonso I, quien afirma en su testamento: "todo esto lo hago para (...) la remisión de mis pecados y para merecer un lugar en la vida perdurable" ${ }^{\prime 89}$. Esta motivación penitente se comprende a partir de St 5,20: "quien convierte a un pecador de su errado camino salvará su alma de la muerte y cubrirá la muchedumbre de sus pecados" (cfr. Ez 3,19-21; 1Pe 4,8). En definitiva, parece que este rey pretendió otorgar un carácter penitente y expiatorio al tímpano de la catedral de Jaca y paralelamente quizás también a la orfebrería del Santo Cáliz. Este tímpano, famoso por su innovador crismón trinitario, está datado hacia $1115^{90}$, fecha que coincide con la presencia de Pedro Alfonso en la corte aragonesa, de modo que podría ser su autor intelectual ${ }^{91}$.

\section{REFERENCIAS BIBLIOGRÁFICAS}

Aeliani. De Natura Animalium. Londres: Frommanni, 1832. Consultado el 18 de diciembre de 2017. https://archive.org/stream/denaturaanimaliu01aeli\#page/ 2/mode/2up.

Alonso, Luis. La Biblia de Nuestro Pueblo. Bilbao: Mensajero, 2011.

Athénée de Naucratis. Le Livre III des Deipnosophistes. Consultado el 18 de diciembre de 2017. http://remacle.org/bloodwolf/erudits/athenee/livre3.htm\# ftnref93.

Barnes, Albert. Notes on the New Testament. Dallas: GraceWorks, 2008. Consultado el 29 de noviembre de 2017. http://sacred-texts.com/bib/cmt/ barnes/rev002.htm.

$87 \mathrm{http}: / /$ www.romanicoaragones.com/0-Jacetania/06-Catedral04a.htm (dintel en tímpano de la portada oeste).

88 La segunda muerte (Ap 2,11; 20,6.14; 21,8) también es mencionada por Pedro Alfonso: "el pecado de Adán fue doble, espiritual y corporal (...). Así soportó castigo doble, esto es, muerte del cuerpo y muerte del alma" (Pedro Alfonso, Diálogo, 358).

89 José Ángel Lema, Colección Diplomática de Alfonso I de Aragón y Pamplona (San Sebastián: Eusko Ikaskuntza, 1990), 328-339 (ref. 241 y 242).

90 Véase: http://www.claustro.com/crismones/webpages/Huesca/CrismonFicha_Jaca_I.htm

91 Este teólogo afirma que "sin penitencia no puede haber expiación posible" [de los pecados] (Pedro Alfonso, Diálogo, 392). Citas paralelas: Is 58,6-8; Mt 25,34-40. Véase Catecismo de la Iglesia Católica 1459. 
Bartina, Sebastián. “Apocalipsis de San Juan”. En La Sagrada Escritura, Nuevo Testamento III (Madrid: BAC, 1962).

Beda. "Explicación al Apocalipsis". En La Biblia Comentada por los Padres de la Iglesia: Apocalipsis, editado por William C. Weinrich. Madrid: Ciudad Nueva, 2010.

Beltrán, Antonio. Estudio sobre el Santo Cáliz de la Catedral de Valencia, $2^{a}$ ed. Valencia: Instituto Roque Chabás, 1984.

Blasco, Agustín. "La Doble Interpretación de la Inscripción del Pie del Santo Cáliz”. Linteum 60 (2016): 13-18, 23-31.

Braude, William Gordon, trad. The Midrash on Psalms, vol. II. New Haven: Yale, 1959.

Braude, William G. y Israel J. Kapstein, trad. Pesikta de-Rab Kahana. London: Jewish Society, 1975.

Burrows, Eric. "The Pearl in the Apocalypse". Journal of Theological Studies 43 (1942): 177-179.

Clarke, Adam. Commentary on the Whole Bible, vol. 6B. Dallas: GraceWorks, 2008. Consultado el 29 de noviembre de 2017. Comentario a Ap 2: $\mathrm{http} / / /$ sacred-texts.com/bib/cmt/clarke/rev002.htm; comentario a Ap 21: http://sacred-texts.com/bib/cmt/clarke/rev021.htm.

Conferencia Episcopal Española. Sagrada Biblia: Versión oficial de la Conferencia Episcopal Española. Madrid: BAC, 2010.

D’Aragon, Jean-Louis. "Apocalipsis". En Comentario Bíblico San Jerónimo, tomo IV, editado por Raymond E. Brown, J. A. Fitzmyer y R. E. Murphy (Madrid: Cristiandad, 1972), 531-592.

De Arlés, Cesáreo. "Expositio in Apocalypsin". En La Biblia Comentada por los Padres de la Iglesia: Apocalipsis, editado por W. C. Weinrich. Madrid: Ciudad Nueva, 2010.

De Beja, Apringio. Comentario al Apocalipsis. Traducido por Alberto del Campo Hernández. Estella (Navarra): Verbo Divino, 1991.

De Cesarea, Andrés. "Comentario al Apocalipsis". En La Biblia Comentada por los Padres de la Iglesia: Apocalipsis, editado por W. C. Weinrich. Madrid: Ciudad Nueva, 2010.

De Huesca, Pedro Alfonso. Diálogo Contra los Judíos. Traducido por Esperanza Ducay. Huesca: Instituto de Estudios Altoaragoneses, 1996.

Del Campo, Alberto y Joaquín González. Beato de Liébana: Comentarios al Apocalipsis de san Juan. Cantabria: Valnera, 2006. Consultado el 1 de noviembre de 2017. http://www.ediciones-valnera.com/pdf/Beato_de_Lieb ana.pdf. 
Düsterdieck, Friedrich. Critical and Exegetical Handbook to the Revelation of John. New York: Funk \& Wagnalls, 1887. Consultado el 29 de noviembre de 2017. https://archive.org/details/criticalexegetic11ds.

Ecumenio. "Oecumenii Commentarius in Apocalypsin". En La Biblia Comentada por los Padres de la Iglesia: Apocalipsis, editado por William C. Weinrich. Madrid: Ciudad Nueva, 2010.

Elsner, Jacobi. Observationes Sacrae in Novi Foederis Libros. Vol II: Epistolas Apostolorum et Apocalypsin Complexus. Utrech, 1728.

Escuela Bíblica de Jerusalén. Biblia de Jerusalén. Bilbao: Desclée De Brouwer, 2009.

Ewald, Heinrich. Die Johanneischen Schriften: Johannes' Apokalypse, vol. II. Göttingen: Dieterischenen Buchhandlung, 1862.

Fekkes, Jan. Isaiah and Prophetic Traditions in the Book of Revelation: Visionary Antecedents and their Development. New York: Bloomsbury, 1994.

Gill, John. Exposition of the Old and New Testaments, vol. VI. Grand Rapids (MI): Baker, 1980. Consultado el 19 de noviembre de 2017. Comentario a Ap 2: http://sacred-texts.com/bib/cmt/gill/rev002.htm; comentario a Ap 21: http://sacred-texts.com/bib/cmt/gill/rev021.htm.

Hastings, James. Dictionary of the Bible vol. III. New York: Scribner, 1902.

Henry, Matthew. Concise Commentary on the Whole Bible, vol. VI. Peabody (MA): Hendrickson, 2009. Consultado el 19 de noviembre de 2017. http://sacred-texts.com/bib/cmt/henry/rev021.htm.

Iglesia Católica. Catecismo. Ciudad del Vaticano: Editrice Vaticana, 1999.

Ironside, Harry A. Estudios sobre el Libro de Apocalipsis. Barcelona: Clie, 1994. Lema, José Ángel. Colección Diplomática de Alfonso I de Aragón y Pamplona. San Sebastián: Eusko Ikaskuntza, 1990. Consultado el 31 de diciembre de 2018. http://www.euskomedia.org/PDFAnlt/fuentes/docs27.pdf.

Martínez, Francisco Javier. "Los Himnos «Sobre la Perla» de san Efrén de Nisibe (De Fide LXXXI-LXXXV)". Salmanticensis 38 (1991): 5-32. Consultado el 29 de noviembre de 2017. https://dialnet.unirioja.es/servlet/articulo?codigo $=669042$.

Mathewson, Dave. A New Heaven and a New Earth: The Meaning and Function of the Old Testament in Revelation 21:1 - 22:5. London: Bloomsbury, 2003. Migne, Jacques Paul, ed. S. Petri Damiani Opera Omnia (Patrología Latina PL 144). París, 1853. Consultado el 29 de noviembre de 2017. http://patristica.net/latina/.

Nácar, Eloíno y Alberto Colunga. Nuevo Testamento. Madrid: BAC, 1980.

Passow, Franz. Handwörterbuch der Griechischen Sprache, vol. III. Leipzig, 1824.

Pikaza, Xabier. Apocalipsis. Estella (Navarra): Verbo Divino, 2015. 
Plinio, Historia Natural. Consultado el 29 de noviembre de 2017. Libro 9: http://penelope.uchicago.edu/Thayer/L/Roman/Texts/Pliny_the_Elder/9*.ht $\mathrm{ml}$; libro 12: http://penelope.uchicago.edu/Thayer/L/Roman/Texts/Pliny_ the Elder/12*.html.

Primasio. "Commentarius in Apocalypsin". En La Biblia Comentada por los Padres de la Iglesia: Apocalipsis, editado por William C. Weinrich. Madrid: Ciudad Nueva, 2010.

Rich, Anthony. A Dictionary of Roman and Greek Antiquities. London: Longmans, 1873.

Rossano, Pietro; Gianfranco Ravasi y Antonio Girlanda. Nuevo Diccionario de Teología Bíblica. Madrid: San Pablo, 1993.

Schick, Eduard. El Apocalipsis. Barcelona: Herder, 1974. Consultado el 8 de febrero de 2018. http://www.mercaba.org/FICHAS/BIBLIA/Ap/CAP-21.htm.

Singer, Isidore, ed. The Jewish Encyclopedia, vol. IX. New York: Ktav, 1906. Consultado el 29 de noviembre de 2017. https://archive.org/details/jewishenc ycloped09sing.

Sociedad Bíblica Católica Internacional. La Biblia Latinoamericana. Madrid: San Pablo, 2002.

Songel, Gabriel. "Patrón de Diseño del Santo Cáliz de Valencia". Revista Bellas Artes 13 (2016): 213-234, consultado el 8 de febrero de 2018, https://riull. ull.es/xmlui/handle/915/6441.

Songel, Gabriel. "Aproximación a la Autoría y Significado de la Inscripción del Santo Cáliz de Valencia". Archivo de Arte Valenciano 99 (2018): 23-33.

Steinsaltz, Adin. Koren Talmud Bavli, vol. 27: Bava Batra. Jerusalem: Koren, 2016. Consultado el 29 de noviembre de 2017. https://www.sefaria.org/ Bava_Batra.75a?lang=bi.

Thayer, Joseph. Thayer's Greek-English Lexicon of the New Testament. Peabody (MA): Hendrickson, 1995. Consultado el 29 de noviembre de 2017. https://www.blueletterbible.org/lang/lexicon/lexicon.cfm?strongs=G5586\&t $=$ MGNT.

Universidad de Navarra. Sagrada Biblia: Edición Digital. Pamplona: Eunsa, 2016. Zarzo, Manuel. "Simbología Bíblica del Santo Cáliz de la Última Cena Venerado en Valencia". Cauriensia 13 (2018): 529-556.

Manuel Zarzo Castelló Departamento de Estadística e I. O. Aplicadas y Calidad Universitat Politècnica de València 46022 Valencia (España) https://orcid.org/00000002-8361-0554 
